\title{
The Challenges and Survival Paths of Traditional News Media in Big Data Era
}

\author{
Mei Xie ${ }^{1, a}$ and Xiao-hong Huan ${ }^{2, b}$ \\ ${ }^{1}$ Mei XIE, Professor of Political Science and Public Administration, University of Electronic \\ Science and Technology of China, Chengdu, China; graduate student of Center for Digitalized \\ Culture and Media, UESTC, University of Electronic Science and Technology of China, Chengdu, \\ China \\ ${ }^{2}$ Xiao-hong Huan, graduate student of Political Science and Public Administration, University of \\ Electronic Science and Technology of China, Chengdu, China; graduate student of Center for \\ Digitalized Culture and Media, UESTC, University of Electronic Science and Technology of China, \\ Chengdu, China \\ axiemei001@163.com, bsuperhuan1@163.com
}

Keywords: big data era, traditional media, transformation, news

\begin{abstract}
The advent of the era of big data has brought tremendous impact on the traditional news industry. In the face of new media information environment, the reform of traditional media in news coverage is also imperative. On the one hand, the application and development of big data technology is an important opportunity for the reformation and transformation of traditional media. On the other hand, the era of big data brings massive information of high quality with the overload of information, which undoubtedly poses some challenges to the transformation of traditional media. Faced with new opportunities and challenges, traditional media need transform to some new modes of communication and information production, in order to give full play to the function of information communication.
\end{abstract}

\section{The Era of Big Data Brings Opportunities for Traditional Media}

With the rapid development and widespread application of information technology and digital technology, vast amounts of data and information generated by human society are being accumulated at a dramatic rate. The word "data" is increasingly being mentioned, and its position in the communication of social information is also more and more important. Based on big data, data mining and data analysis technology have a profound impact on the datamation development of other industries. According to a report by the McKinsey Global Institute, big data is, following the traditional information industry, a cutting-edge technology and can significantly improve production efficiency. It will bring considerable benefit in areas such as government public service, medical service and retail business. The massive data has also become the core of the competition and transformation of major traditional media. According to Frédéric Filloux, general manager of French Digital Group, the big data effectively used by other industries is equally applicable to the digital media industry. In fact, the neglect and omission of traditional media have led to the huge data value from a large number of readers not been excavated. Therefore, the use of behavioral data can enhance the attractiveness of news services to readers and thereby bring greater benefits to media operators.

With the rapid rise of new media, the performance of traditional media in news reports has been declining and even more worrying. Especially in terms of the means of information transmission and release, the new media is striking the traditional media at an unprecedented level. However, the advent of the big data age seems to provide an important opportunity for the development and 
timely transformation of traditional media. It not only promotes the development and transformation of traditional media, changes the mode of news production, and compels the news industry innovate from the fixed mode of textual narrative to data narrative, and the content and mode of information communication in traditional media are also promoted. At the same time, the integration of new media and old media is accelerated. For example, the practice innovation of traditional media in big data era, in other words, data news, is a new form of news report produced by the application of new technologies, such as digital technologies and computers to news reports, which effectively promotes the integration of media.

In addition, big data has also had many transformative effects in news applications, such as protecting original news through data monitoring across the entire network, mining more news material and related information to assist in-depth coverage, pooling mass media coverage and structuring news reports processing and reorganization; learning the audience's needs, media habits and other relevant information through big data analysis, so as to promote the more rational use of frame structure in news report.

In the era of big data, if traditional media can fully tap the application value of big data technology and apply the various information and analysis results provided in news reports to accurately identify its own audiences and customers, it may become a way out for audience reduction and other difficulties.

\section{The Challenges Traditional News Media Faced in the Era of Big Data}

Always considered as the uncrowned king, the vigorous media industry is now facing frequent attacks of new media on medium, mode of communication and reading habit. The rapid development of new media industry has brought tremendous pressure on traditional media and new media has taken a superior position with its technology advantages gradually. Especially in some news reports, traditional media are often left in a passive position and the development of traditional media is in a dilemma. The time-laden paper media is particularly troublesome. Founded fifteen years ago, Jinghua Times announced that it would cease publication since the first day of 2017. The impact of the new media on traditional media has never stopped. The rapid changes often make the traditional media caught off guard. With the advent of the big data era, although the traditional media has undergone some changes and transformations in the way of media production and communication, new media occupy a great advantage on the application of data, which seems to have let the traditional media into a certain development dilemma. Compared with traditional media, new media has obvious advantages in terms of cost, timeliness and information volume based on network technology, but also because of the openness and anonymity of new media, it is especially important to ensure the authenticity and reliability of news information in complicated network information.

Secondly, although traditional media, to a certain extent, has seized the application value of big data and undergone some changes and transformations, it has not completely implemented it and not very successful. There are still several major problems: first, the timeliness of news is still weak, the speed to find clues and dig hot spots is not fast enough, and because of the flaws in traditional media's news communication process, the feedback speed of each channel is not fast enough to quickly know the audience's feedback and reaction after the content is released, which may also affect the coverage of the next phase; second, the traditional media needs to be further strengthened its insight into the needs of users. Sometimes the news delivered does not attract the audience and not form a good interaction with the audience; third, the traditional press media production and distribution process are outdated. From the aspects of "production - release - feedback", there has not been any real contact with each other, and the traditional idea of news production still remains; fourth, the profit mode is still stuck in its original position: singly relying on sections such as advertising.

Finally, in the face of massive data in big data era, it is not easy for traditional media to dig and 
analyze these huge amounts of data. At present, the big data research tools for news practice is not mature in China, while the traditional media lacks the data processing capabilities and mostly rely on software and hardware service providers. In the meantime, digging out news from massive data and doing a good job of visualizing news require special talents and teams. Only when journalists master a variety of data technologies, the credibility and value of data can maximize and ensure the authenticity of the news. The current shortage of talent of this area in China ask for relevant majors opened in colleges and universities to train qualified personnel.

\section{The Survival Paths of Traditional News Media in the Era of Big Data}

Regard Content as the King and Make Innovation

The era of big data, on the one hand, provides people with abundant information resources. On the other hand, huge and complicated information brings about overloaded information and even information burden for the audience. Supported by network, new media has a lot of information yet mixed in quality which is a major drawback in its development. In the age of poor information, the traditional media that always insists on the principle "content is the king" can seize the opportunity. Because of the low quality and fragmentation led by inflated information, traditional media can seize people's demand for high-quality and deterministic information in the information flooding to survive in the era of big data.

Emphasis on in-depth coverage. In the era of "everyone has a microphone”, every citizen can spread news by typing on one's keyboard and reporting news is no longer the exclusive power of an official journalist. How can traditional media better cover the news and maintain their positions? Nowadays, the in-depth reports have not lost their place due to the change of the media environment. The media that mainly reports in depth have not been hit too much by the new media. With the support of big data technology, the traditional media can dig deeper into the news information and the value of news. Convincing narratives combined with abundant digital information can help journalists more vividly and visually report on the news that is complex and difficult to understand.

By digging data on which the reporter's work is based, the news media provide readers with insights through scientific analysis and transform the abstract and macro social issues into easy-to-understand content, common to ordinary people. Analyzing the laws and trends in the development of things in complex situations provide predictive content to people's decisions. Event analysis and interpretation based on big data technology are more reliable than interviewers and journalists' own judgement. Whether it is data news, news visualization or interactive news, in-depth coverage should be the straw that traditional media must capture.

Discover new topics from old news topics. Using big data to analyze the old news topics can not only analyze the audience's needs and feedback, promote a more reasonable application of the news report framework, but also broaden the idea and scope of coverage. In the news coverage of the missing event of Malaysia Airlines, the media reported daily the latest news on search and rescue work. During the search and rescue at sea, the aircraft involved in the search and rescue also found suspected debris at the sea surface. The satellite also sent back images suspected of being debris from the aircraft. However, the suspected floating debris recovered by the search and rescue vessel was rubbish. A news medium used data analysis to capture the marine litter as news topic and reported on issues such as the type of marine litter, both to convey the new information to the audience and to broaden the coverage of the report. Yan Wenbin, director of the external editorial department of Xinhua News Agency, put forward that the thought brought by the Internet is that the news is now audiences-oriented, for the audiences are no longer passive recipients. Yet, the principle "content is the king" is not obsolete. In order to better serve the audience, the media need enhance the broadcasting power, influence and credibility, improve the quality of news and focus on content development. 


\section{Pay Attention to Users and Information Services}

In the era of big data, the traditional media, simply adhere to the concept of "content is the king" can no longer meet the needs of customization. The key is to changing spread thinking and operating idea. Otherwise, the news media even with high-quality content resources is difficult to play its value, if not effectively meet the needs of users. Therefore, under the background of big data era, the traditional media needs to establish the concept of user service, provide users with personalized information services, change the thinking of news production, and achieve the subversion of the mode.

Employing big data analysis to agenda-setting. Get the audience's attention on the relevant reports and enhance the focalization of the report through the big data analysis. The media first report the issue to the audience, and then, through the big data analysis of the audience's response to these issues, choose which issue should be further reported in detail. For example, there are two issues that are set by the two topics, the burglary of criminals and the occurrence of a major car accident in a certain place. The audience will react differently on these two topics and the media will analyze the feedback of the audience by using big data to make the next issue.

Explore user needs deeper. Traditional media's omission in face of customization and anti-popularization of the users lead to a gradual loss of fixed audience. Most importantly, traditional media needs big data to mine user needs, in order to have a good interaction with users. The key to promoting the transformation of traditional news media is to change the concept of news.

Traditional news media should rely on the thought of "information service" and make use of big data to realize intelligent matching of information. Only to know what the audience want to see, what kind of information the audience want to learn, and figure out the audience's taste, the accurate and high-quality content can be produced. This requires the traditional news media to create technology platform for mining user information and cloud information service platform for screening information, so as to better serve the audience instead of unidirectionally providing news to the audience.

Build Brand Advantage

Compared with some new media, traditional news media have some advantages in brand recognition nationwide. However, this historical reading habit or viewing preference is gradually losing under the new media's impact. In the era of big data, traditional media should grab the chance to strengthen the brand effect, consolidate the basic audience, and actively implement the strategy of going out to participate in the international media competition. Traditional media need to change the "concept" thinking or "bright spot" thinking of "content gene" and gradually establish the management thinking of "commercial gene" and the technical thinking of adapting to "technology gene". Traditional news media should, from the perspective of the audience, form their own style based on precise audience information delivery and emotional exchange; integrate the brand positioning into its brand characteristics through the news and so on, thus form a truly valuable commercial model.

\section{Conclusion}

The advent of the big data age has not only brought opportunities and challenges to the development of traditional news media, but more importantly, it has promoted the reform and innovation of traditional news media concepts and communication thinking, as well as reflections triggered by a series of practical innovation by traditional news media based on big data technology. It is true that big data can bring some help to the development of traditional news media. However, not all news can apply big data technology. The era of "robot writing news" also brings many drawbacks. Big data technology can not completely solve the difficulties traditional news media encountered in their development, but what we need to be clear is that a series of thinking and discussions caused by the impact of the big data era on traditional news media still need to be 
continued.

\section{References}

[1] Junrong Wang, Shuangshuang Cui. The Transformation and Breakthrough of Traditional Media in the Big Data Era [J]. Media Observations, 2014, (4).

[2] Ziying Li. Thought on Traditional Media Transition in Big Data Era[J]. Public Communication of Science \& Technology, 2014, (3).

[3] Bin Wang. Big Data and News Idea Innovation [J]. Editorial Friend, 2013, (6).

[4] Quanzhong Guo. The Key to the Transformation of Traditional Media in the Big Data Era [J]. Chinese Journalist, 2013, (7).

[5] Benqian Li. The Innovation in Communication Science in the Era of Big Data [M]. 2016, (1). 